\title{
Evaluating Electrical Anisotropy Parameters in Miocene Formations in the Cierpisz Deposit
}

\author{
Maria BAŁA and Adam CICHY
}

AGH University of Science and Technology, Department of Geology,

Geophysics and Environmental Protection, Kraków, Poland; e-mails: bala@geol.agh.edu.pl, cichy@agh.edu.pl (corresponding author)

\section{Abstract}

The electrical anisotropy of rocks is generally an effect of alternating layers of thin-bedded sandstones and shales with clear lamination.

Thin-bedded rock sequences can be treated as an anisotropic medium described by two resistivities: horizontally to the bedding $R_{H}$ and vertically to the bedding $R_{V}$. Such sequences have fairly low resistivity and, as a result of poor vertical resolution of conventional electric tools, one can sometimes fail to distinguish them from the adjoining shales.

This paper presents the possibility of calculating the anisotropy parameters based on resistivity logs recorded with a laterolog tool (DLL) and an induction tool HRAI. We have also performed an analysis of the ambiguity of the results and attempts to assess the water saturation (SW) generating cross-plots based on calculated resistivities, $R_{H}$ and $R_{V}$.

It is very important to correctly evaluate the resistivity of sandstone interbeds when calculating water saturation (SW) and hydrocarbon saturation (SG), in formulating an integrated quantitative interpretation of anisotropic formations.

Key words: electrical anisotropy, dual laterolog tools, induction device HRAI, horizontal resistivity, vertical resistivity. 


\section{INTRODUCTION}

The objective of this paper is an attempt to evaluate three electrical anisotropy parameters, namely: horizontal resistivity $\left(R_{H}\right)$ vertical resistivity $\left(R_{V}\right)$, and the anisotropy coefficient $(\lambda)$. This can be achieved by measurements carried out using different electrical tools, namely an induction tool with high vertical resolution, HRAI, and dual laterolog tools, LLS and LLD. It is known from the theory that apparent resistivity measured using an induction device, HRAI, provides information on horizontal resistivity $\left(R_{H}\right)$ while a controlled device LLD records apparent resistivity, which is a result of the influence of both horizontal $R_{H}$ and vertical $R_{V}$ resistivities (Bała 2011). The problem of electrical anisotropy of rocks and its influence on the resistivity measured in boreholes using electrical tools has been dealt with by a number of researchers for many years (Kunz and Moran 1958, Zajkowskij et al. 1965, Dachnov 1967, Chemali et al. 1987, Klein 1993, Bittar and Rodney 1994, Klein et al. 1995, Hagiwara 1996, Yang 2001, Anderson et al. 2002, 2008; Faivre et al. 2002, Tabanou et al. 2002, Rosthal et al. 2003). The author of this paper has recently been engaged in an evaluation of electric anisotropy of sandy-shale Miocene rocks, based on resistivity logs recorded using laterolog tools and induction tools in boreholes (Bała 2009, 2011).

The electrical anisotropy of rocks may be caused by a number of factors, but the most important ones include alternating layers of thin-bedded sandstones and shales with a clear lamination. Anisotropy in the microscopic scale is caused by the internal arrangement of grains of different size, which are elongated in one direction, or by different pore sizes.

In Miocene formations of the Carpathian Foredeep one can observe the alternating thin layers of sandstone, mudstone, and clay. Thin-bedded rock sequences can be treated as an anisotropic medium described by two resistivities: horizontally to the bedding $\left(R_{H}\right)$ and vertically to the bedding $\left(R_{V}\right)$.

Such sequences have fairly low resistivity and, as a result of the poor vertical resolution of conventional electric tools, one can fail to distinguish them from the adjoining shales. Mollison et al. (2001) called this a pay zone with low resistivity contrast. An example of such deposits are turbidites from a Miocene basin plain and submarine fans that are very important to hydrocarbon accumulation. Those deposits contain thin beds of sandy-shalymudstone heteroliths from the Lower and Middle Sarmatian (Myśliwiec 2004).

Based on well logging data analysis, well C-3 in the Cierpisz structure was chosen for testing, logging was carried out in order to evaluate electrical anisotropy, DLL and HRAI. 


\section{GEOLOGICAL SETTING}

The Cierpisz gas deposit is located in sand-shale Sarmatian sediments in the southern part of the Carpathian Foredeep, near the great gas deposit of Czarna Sędziszowska (Fig. 1).

The detailed study of SED dipmeter logs permitted the evaluation of structures and dip angles in well C-3.

In shallow sections of the well there occur regular layered alternating series of shales, mudstones, and sandstones, which have been deposited in a low-energy environment. The deposits lie almost horizontally or are dipping at a small angle to the north.

The underlying transgressive series of sandstones and mudstones are also dipping at small angles in the same direction.
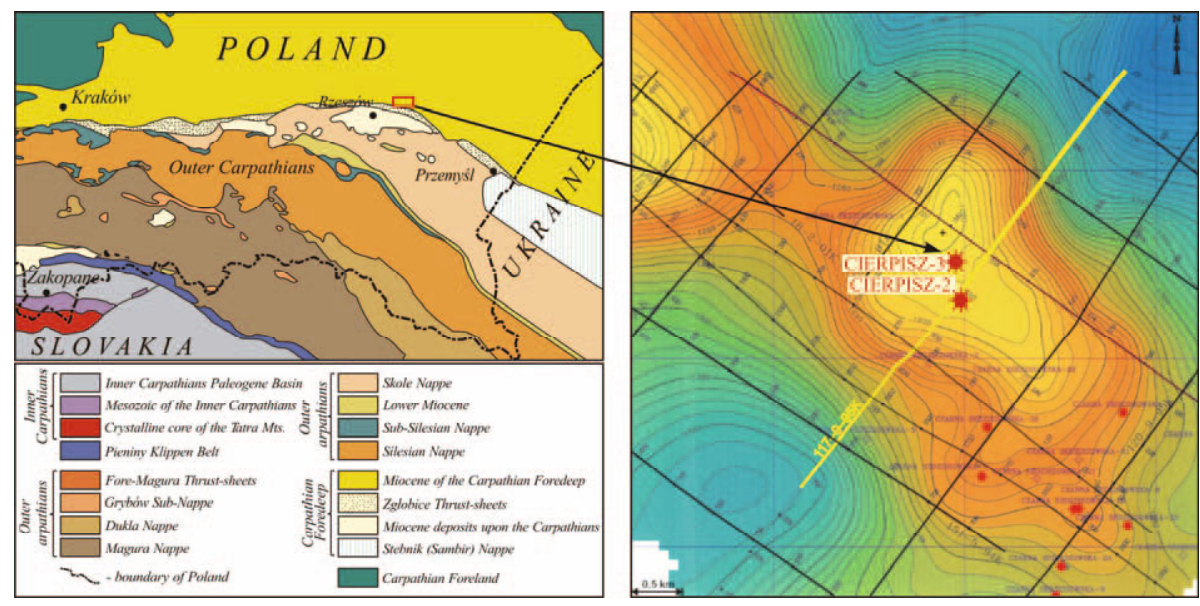

Fig. 1: right: Location of the Cierpisz-3 well in the structural map of 9th gas horizon of the Cierpisz gas deposit (Syrek-Moryc 2006); left: Schematic map of Carpathians and Carpathian Foredeep: 1 - northern range of Miocene formations, 2 - northern border of the Carpathians, and 3 - boundaries of tectonic units of the Outer Carpathians (Karnkowski 1999).

\section{ANISOTROPY OF THE ELECTRICAL PROPERTIES OF ROCKS}

Most of sedimentary rocks have anisotropic properties. The electric current flows easily along the bedding rather than perpendicular to it.

In a uniform and anisotropic medium, the potential of the electric field $(U)$ at an arbitrary point of the medium, decreases inversely proportionally to the distance $(r)$ from the source of the direct current, with an intensity of $I$.

$$
U=\frac{I \cdot R_{a v}}{4 \pi \cdot r \cdot \sqrt{1+\left(\lambda^{2}-1\right) \cdot \cos ^{2} \alpha}},
$$


where

$$
\lambda^{2}=R_{V} / R_{H}
$$

is the anisotropy coefficient,

$$
R_{a v}=\sqrt{R_{V} \cdot R_{H}}
$$

is the geometric mean, $R_{V}$ is the electric resistivity measured vertically to the bedding, $R_{H}$ is the electric resistivity measured horizontally to the bedding, and $\alpha$ is the angle between the layer dip and the vertical to measurement direction.

For given values of $R_{a v}$ and $\lambda$, the potential depends on the direction (angle $\alpha$ ) along which one studies how the $U$ changes depend on $r$.

Having assumed that the borehole diameter and drilling mud are neglected (no borehole) in a uniform and anisotropic medium, the measured resistivity $\left(R_{a}\right)$ does not depend on type and size of the tool (lateral or normal tool) (e.g., Dachnov 1967, Kunz and Moran 1958).

$$
R_{a}=\frac{\lambda \cdot R_{H}}{\sqrt{1+\left(\lambda^{2}-1\right) \cdot \cos ^{2} \alpha}} .
$$

For the case of $\alpha=0^{\circ}$

$$
R_{a}^{(v)}=\frac{\lambda \cdot R_{h}}{\lambda}=R_{h}
$$

and for the case of $\alpha=90^{\circ}$

$$
R_{a}^{(h)}=\lambda \cdot R_{h}
$$

thus

$$
R_{a}^{(h)}>R_{a}^{(v)}
$$

This means that the apparent resistivity $R_{a}^{(v)}$ measured normal to the strike direction is less than $R_{a}^{(h)}$ measured along the strike direction, although it is known that the true resistivity of an anisotropic formation, normal to its stratification $R_{v}$, is greater than parallel to the plane of stratification $R_{h}$. This phenomenon is called "the paradox of anisotropy".

However, due to the presence of the borehole and of the tool, the real measured values differ from the theoretical ones (Moran and Gianzero 1979).

In our case, the paradox of anisotropy does not appear due to the big diameter of the borehole $(0.216 \mathrm{~m})$ and the presence of mud. 
Based on dipmeter measurements in well $\mathrm{C}-3$ one can observe that the dips in layers in the reservoir zones do not exceed 1-3 $3^{\circ}$. Also, the small inclination of a borehole does not have any great impact in terms of a proper evaluation of electrical anisotropy parameters.

This confirms that a given methodology may be used to interpret $R_{H}$ and $R_{V}$ in the C-3 well.

\subsection{Modelling of distribution of $\boldsymbol{R}_{H}$ and $\boldsymbol{R}_{V}$ with depth}

An attempt was made to model the resistivity depth distributions of $R_{H}$ and $R_{V}$ for the assumed "synthetic" model, composed of a dozen layers with varying thickness and resistivity (Fig. 2). The model was constructed based

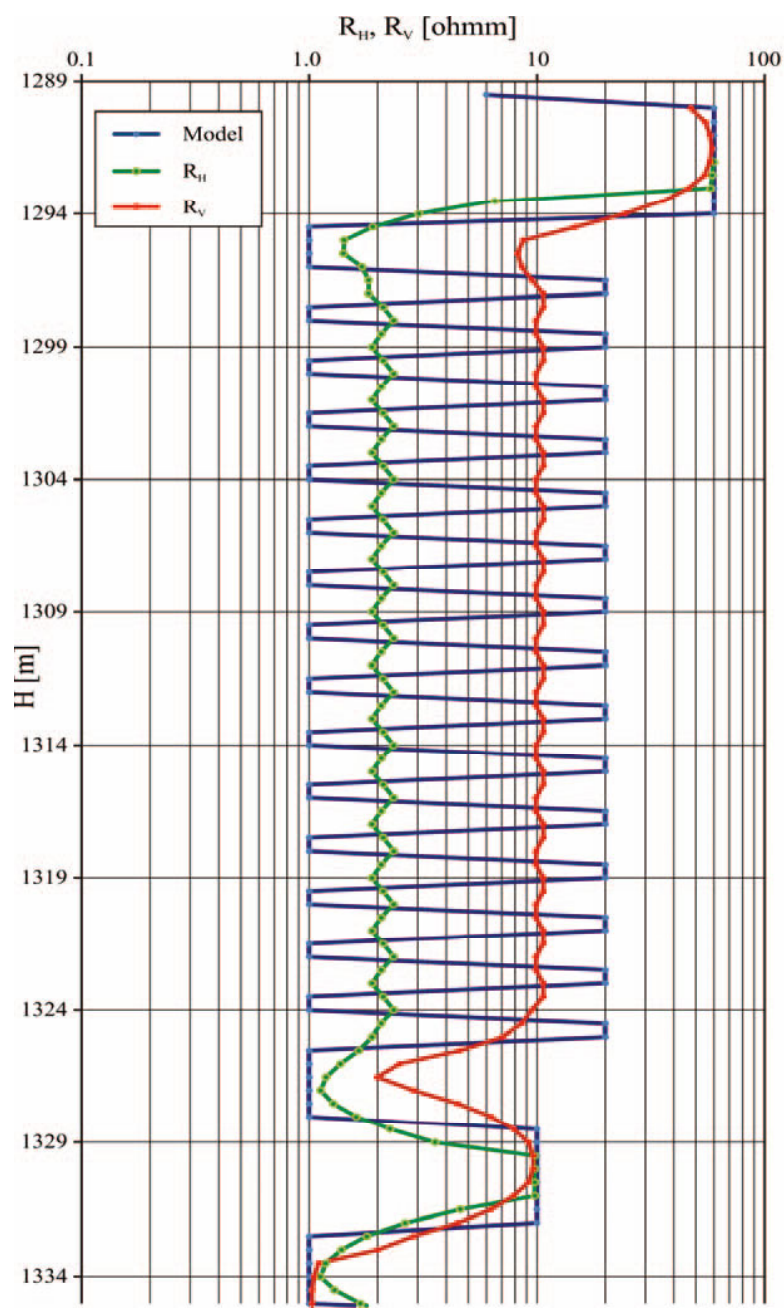

Fig. 2. Resistivities $R_{H}$ and $R_{V}$ as a function of depth for the assumed model. 
on apparent resistivity logs from a depth interval of 1290.0 to $1338.0 \mathrm{~m}$. In addition to single layers with the thickness ranging from 2.0 to $5.0 \mathrm{~m}$ and resistivity $R_{t}$ ranging from 10 to $60 \mathrm{ohmm}$, it was assumed that there was an anisotropic series built of higher-resistivity sandstone interbeddings $\left(R_{\mathrm{sand}}=20 \mathrm{ohmm}\right)$ and low-resistivity shale interbeddings $\left(R_{\mathrm{sh}}=1 \mathrm{ohmm}\right)$. The thickness of each layer was taken as $h=0.5 \mathrm{~m}$.

The calculations were performed using the following formula (Tabonou et al. 2002, Quirein et al. 2012):

$$
\begin{aligned}
& R_{V}(z)=\int_{-H / 2}^{H / 2} R_{t}\left(z^{\prime}\right) F_{H}\left(z-z^{\prime}\right) d z^{\prime}, \\
& \frac{1}{R_{H}(z)}=\int_{-H / 2}^{H / 2} \frac{F_{H}\left(z-z^{\prime}\right)}{R_{t}\left(z^{\prime}\right)} d z^{\prime},
\end{aligned}
$$

where $R_{t}$ is the assumed resistivity of model layers, $F_{H}\left(\mathrm{z}-\mathrm{z}^{\prime}\right)$ is the convolution of the log (here of the model) with a constant sampling interval and accepted filter (e.g., Gaussian filter), and $H$ represents calculation of window size.

The assumed model (blue curve) and calculated horizontal resistivity (green curve) and vertical resistivity (red curve) are shown in Fig. 2. It can be seen that for the complex anisotropic beds, the horizontal resistivity $\left(R_{H}\right)$ approaches $2 \mathrm{ohmm}$, vertical resistivity $\left(R_{V}\right)$ approaches $10.29 \mathrm{ohmm}$, and the anisotropy coefficient $\lambda=2.01$.

These models confirm the observed very low resistivity in zones of thin silty sundstone interbedding in the Miocene.

\section{DETERMINATION OF RESISTIVITY $\boldsymbol{R}_{H}$ AND $\boldsymbol{R}_{V}$ AND ANISOTROPY COEFFICIENT IN LAYERS OF MIOCENE SHALY SANDSTONES}

\subsection{Analysis of measured data}

Table 1 contains electric logs and measurement intervals in well C-3 and results of tester formation.

The measurements in well C-3 were conducted in 2004 by Geofizyka Kraków with the use of a Halliburton DDL-D logging unit. Due to the good quality of the borehole, the data are of good quality. An exception was HRAI logging, in which a lot of disturbances were observed being a result of anomalous high-conductivity zones. The disturbances were partly eliminated with the use of correction procedures (C-3 Well 2004). 
Table 1

Electric logs in well C-3

\begin{tabular}{|c|l|c|l|}
\hline $\begin{array}{c}\text { Borehole } \\
\text { (year of drilling } \\
\text { completion) }\end{array}$ & Electric logs & $\begin{array}{c}\text { Measurement } \\
\text { interval } \\
{[\mathrm{m}]}\end{array}$ & \multicolumn{1}{c|}{$\begin{array}{c}\text { Results } \\
\text { of tester formation }\end{array}$} \\
\hline & SP & $220-1497$ & $\begin{array}{l}1330-1346 \mathrm{~m} \text { gas } \\
V=235 \mathrm{~m}^{3} / \mathrm{min}\end{array}$ \\
C-3 & DIL + LL3 & $220-1497$ & $1394-1440 \mathrm{~m}$ gas \\
$(2004)$ & SED & $220-1497$ & $V=129 \mathrm{~m}^{3} / \mathrm{min}$ \\
& HRAI & $220-1499$ & $1450-1455 \mathrm{~m}$ gas \\
& & & \\
& & & \\
\end{tabular}

\subsection{Results of calculations in well C-3}

Horizontal resistivity $\left(R_{H}\right)$ and vertical resistivity $\left(R_{V}\right)$ were calculated based on available data recorded with an induction HRAI tool and dual laterolog DLL tool.

After Hagiwara (1996), Faivre et al. (2002), Tabanou et al. (2002), and Bała (2011), it was assumed that the deep penetration induction tool $(3.048 \mathrm{~m})$ with high vertical resolution $(0.3048 \mathrm{~m})$ can record resistivities that are comparable to horizontal resistivity for vertical borehole and horizontally layered rock mediums. The authors also suggest that the resistivity measured with a LLD tool is similar to the geometrical mean of resistivity $\left(R_{a v}\right)$, and based on this it is easy to calculate $R_{V}$ and $\lambda$.

Figures 4 and 5 show HRAI and DLL logs for depth intervals of 910-952 and 1290-1325 m, which included layers partly saturated with gas and formation water with different shale volumes. Paths 2 and 3 present the results of quantitative interpretation made by Geofizyka Kraków in 2004, while path 4 shows selected dipmeter logs (PDD1, PDD2, PDD3), followed by: Dual Laterolog curves (path 5), some HRAI logs after depth correction (path 6), calculated anisotropy parameters $R_{H}, R_{V}$ (path 7), and the anisotropy coefficient $\lambda$ (path 8). Figure 3 presents captions to logs and calculation results.

In studying the logs in Figs. 4 and 5 one can see that the calculated anisotropy coefficient is highly variable. Its value oscillates from 1 to 2.2 and locally exceeds 2.3 . At a depth interval of $910-952 \mathrm{~m}$ the anisotropy coefficient considerably increases $(1.2<\lambda<2.3)$. The lithology of that depth interval includes shales intercalated with sandstones and mudstones with a significantly increased porosity (Fig. 4).

At a depth interval of 1290-1325 m one can observe the high variability of $\lambda$ values while the increased values are usually related with higher shaliness (Fig. 5). 


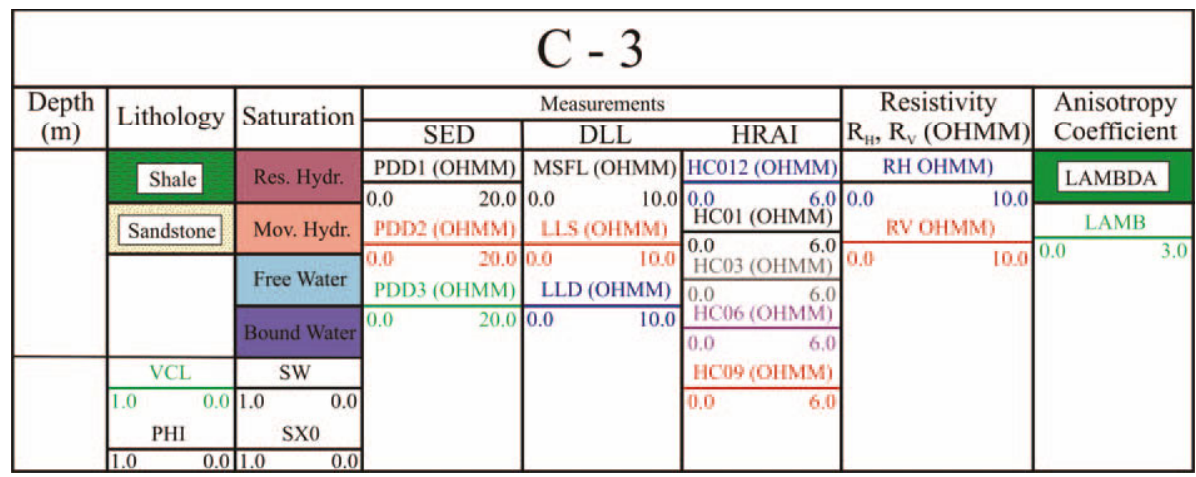

Fig. 3. Headline for Figs. 4 and 5 showing measurements and calculated anisotropy parameters.

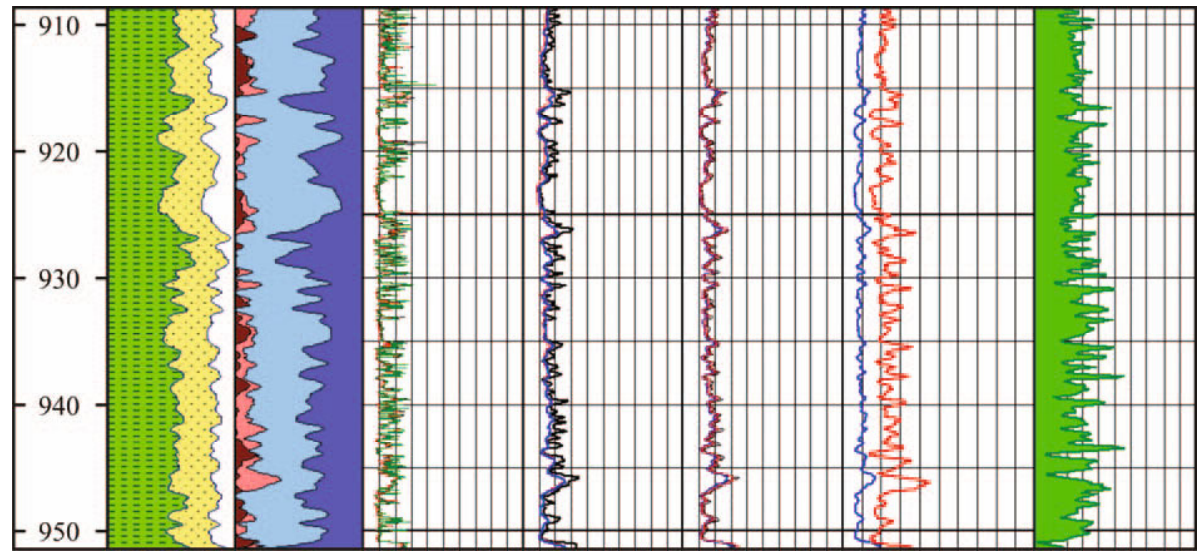

Fig. 4. Well logs and calculation results for depth interval of 910-952 m.

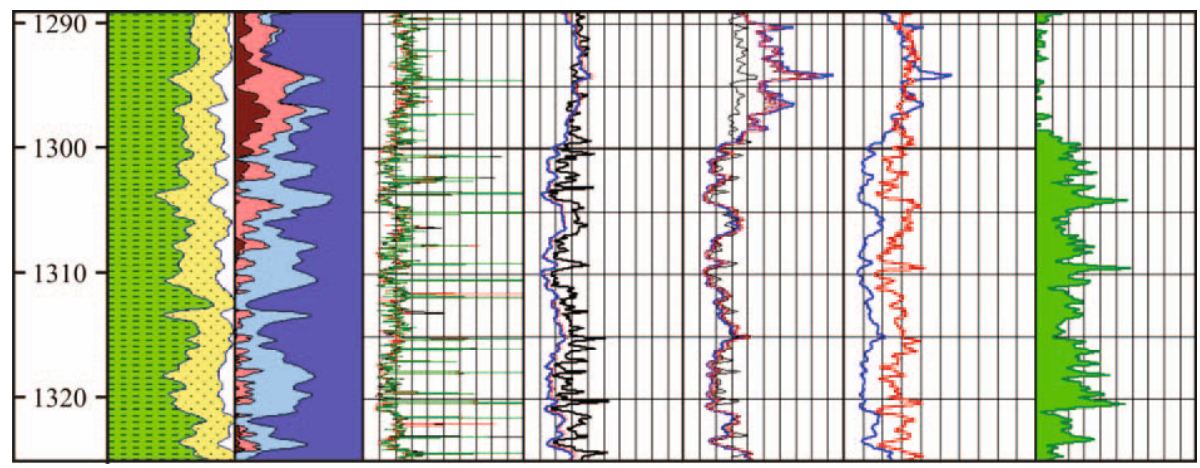

Fig. 5. Well logs and calculation results for depth interval of 1290-1325 m. 


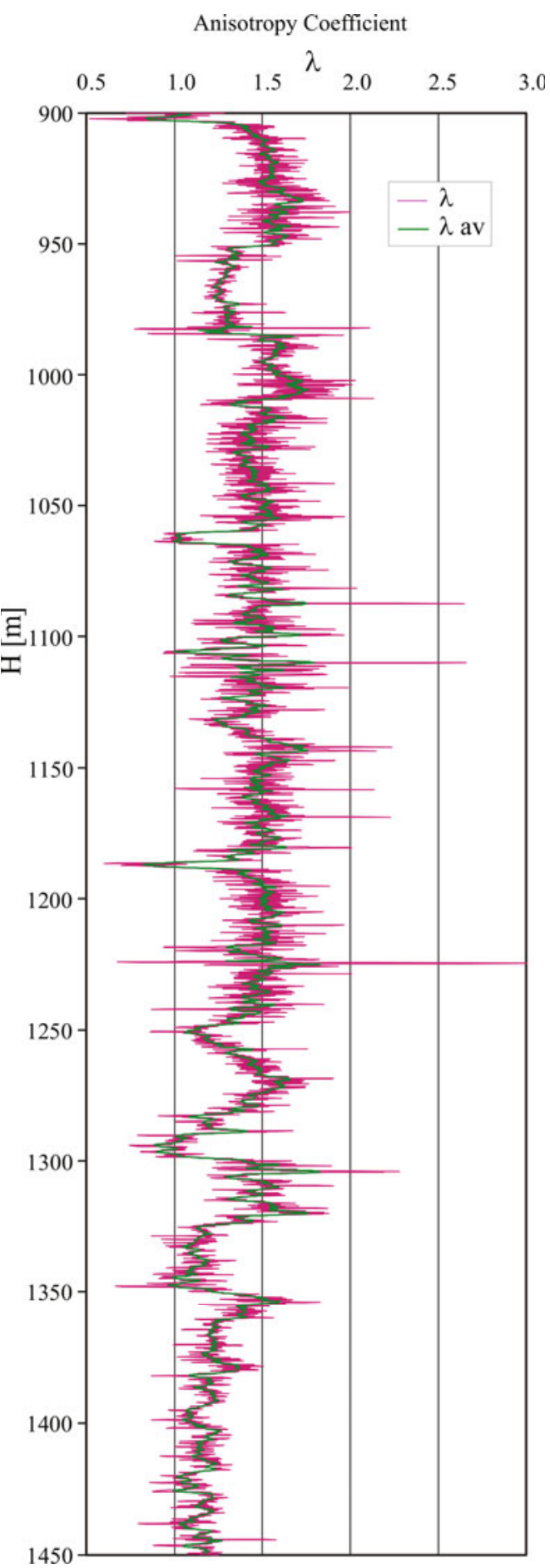

Fig. 6. Anisotropy coefficient versus depth for a depth interval of 900-1450 m. $\lambda$ - value calculated for each measurement point, $\lambda$ av - value averaged with a13-point filter. 
To better illustrate the changes of $\lambda$ with depth $H$, we present the plot in Fig. 6; the plot shows the values calculated for each measurement point with a step of $0.1 \mathrm{~m}$ and the value averaged with a 13-point filter (moving average). The moving average value smoothes the oscillations and eliminates extreme values that can be a result of the misfit of the log depth.

Based on the averaged values of $\lambda$ we calculated the mean, minimum, and maximum values of the anisotropy coefficient for the whole interval of 900 to $1450 \mathrm{~m}$. The results for selected intervals are given in Table 2 .

Table 2

Mean, minimum, and maximum values for the electric anisotropy coefficient (after averaging with a 13-point filter) for selected depth intervals. Well C-3.

\begin{tabular}{|c|c|c|c|l|}
\hline $\begin{array}{c}\text { Depth interval } \\
{[\mathrm{m}]}\end{array}$ & \multicolumn{2}{|c|}{ Electric anisotropy coefficient $\lambda$} & \multicolumn{1}{|c|}{ Remarks } \\
\cline { 2 - 4 } & $\begin{array}{c}\text { Mean } \\
\text { value }\end{array}$ & $\begin{array}{c}\text { Minimum } \\
\text { value }\end{array}$ & $\begin{array}{c}\text { Maximum } \\
\text { value }\end{array}$ & \multicolumn{1}{|c|}{$\begin{array}{l}\text { Shales, medium shaliness, } \\
\text { sandstone intercalations, } \\
\text { high porosity, anisotropy(?) }\end{array}$} \\
\hline $1010.0-1059.4$ & 1.464 & 1.310 & 1.628 & $\begin{array}{l}\text { Sandstone and shale, } \\
\text { anisotropy }\end{array}$ \\
\hline $1064.5-1100.0$ & 1.471 & 1.158 & 1.750 & $\begin{array}{l}\text { Shale and sandstone, } \\
\text { anisotropy }\end{array}$ \\
\hline $1109.5-1184.9$ & 1.481 & 1.220 & 1.794 & $\begin{array}{l}\text { Shale with sandstone inter- } \\
\text { calations, gas saturation, } \\
\text { high porosity, anisotropy(?) }\end{array}$ \\
\hline $1192.0-1243.7$ & 1.494 & 1.292 & 1.830 & $\begin{array}{l}\text { Shale with sandstone inter- } \\
\text { calations, variable gas } \\
\text { saturation, anisotropy(?) }\end{array}$ \\
\hline $1299.5-1321.1$ & 1.501 & 1.232 & 1.828 & $\begin{array}{l}\text { Shale with sandstone } \\
\text { intercalations, anisotropy }\end{array}$ \\
\hline
\end{tabular}

Due to intercalations of the sandstones and shales and increased values of coefficient $\lambda$ observed in them, some intervals from Table 2 can be regarded as anisotropic layers.

The detailed study of high-resolution logs measured with a SED dipmeter shows that anisotropic layers can occur there.

The table indicates three layers in which we can deal with anisotropy or variable gas saturation, or increasing influence of the mud. These layers are indicated with a question mark "?".

Studying the calculated anisotropy coefficients one should: 
- Eliminate intervals in which resistivity changes are observed as a result of mud filtrate invading the borehole environment (flushed zone), particularly when the mud has increasing effects on resistivity. There is still the phenomenon of equivalence observed by Kunz and Moran (1958), who indicated that an anisotropic layer with the infinite thickness $(h \rightarrow \infty)$ is equivalent to an isotropic, radially inhomogeneous layer whose resistivity varies according to:

$$
R_{\mathrm{eq}}=\frac{R_{a v} \cdot r^{\prime}}{\lambda \cdot r^{\prime}-(\lambda-1) \cdot a} \quad \text { for } \quad r>a,
$$

and

$$
R_{\mathrm{eq}}=R_{m} \quad \text { for } \quad r^{\prime}<a \quad \text { and } \quad r^{\prime}=\frac{r}{a},
$$

where $r$ is the radial component, $a$ is the borehole radius, and $R_{m}$ represents mud resistivity.

When resistivity distributions $R_{\text {eq }}$ given by Eqs. 7 for $R_{H}=1.5 \mathrm{ohmm}$ and $\lambda=2$ were compared with the $R_{a}$ distribution under the assumption of a shallow invaded zone, in the water-bearing layer with increased mud effect (Bała 2011), it was noted that resistivity changes were similar; this may be misleading and suggest the anisotropy in a layer with radially variable resistivity.

- It was also observed that higher gas saturation and higher porosity caused an increase in $R_{V}$ and this in turn resulted in increased values of $\lambda$ but did not correspond to anisotropic zones (such zones are marked in Table 2 by a question mark "?”).

\section{ANALYSIS OF AMBIGUITY OF THE RESULTS}

\subsection{Effect of sandstone and shale volume on the anisotropy coefficient}

Resistivities $R_{V}$ and $R_{H}$ for anisotropic formations of a laminar model (Klein 1993, Mollison et al. 2001, Bała 2011) can be calculated from the simplified formula:

$$
\begin{gathered}
R_{V}=V_{\text {sand }} \cdot R_{\text {sand }}+V_{s h} \cdot R_{s h}, \\
R_{H}=\frac{R_{\text {sand }} \cdot R_{s h}}{V_{\text {sand }} \cdot R_{s h}+V_{s h} \cdot R_{\text {sand }}},
\end{gathered}
$$

and

$$
V_{\text {sand }}+V_{s h}=1 .
$$

It can be seen that the varying proportions of sandy and shale fractions influence the values of resistivities, $R_{H}$ and $R_{V}$, and the anisotropy coefficient $\lambda$. 
a)

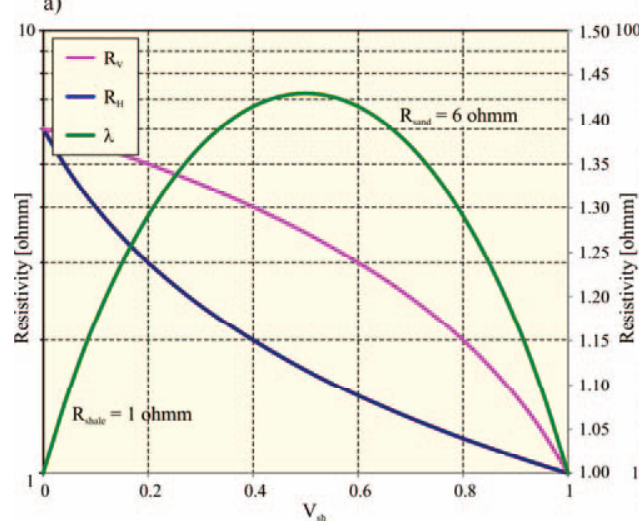

b)

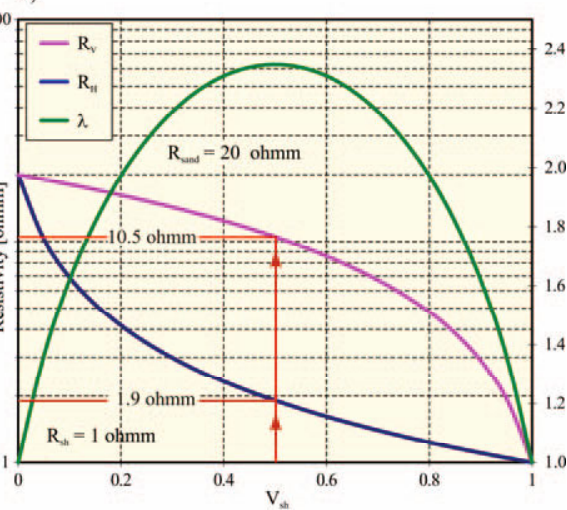

Fig. 7. Resistivity as a function of shale volume. Calculations for: (a) $R_{s h}=1 \mathrm{ohmm}$, $R_{\text {sand }}=6 \mathrm{ohmm}$; and( b) $R_{\text {sh }}=1 \mathrm{ohmm}, R_{\text {sand }}=20 \mathrm{ohmm}$. Laminar model.

Figure 7 presents plots of resistivity versus shale volume for a laminar model and $R_{s h}=1 \mathrm{ohmm}$ and $R_{\text {sand }}=6$ and $20 \mathrm{ohmm}$, which are most characteristic for the Miocene deposits.

It can be seen that the anisotropy coefficient first grows from 1 (scale on the left) for $V_{s h}$ rising from 0 to $50 \%$ when it attains its maximum: for (a) $\lambda=$ 1.43 , and for (b) $\lambda=2.35$, then it decreases to 1 along with increasing shale volume. It can also be read that for $V_{s h}=0.5$ (model (b)) resistivity $R_{V}=10.5 \mathrm{ohmm}$ and $R_{H}=1.9 \mathrm{ohmm}$.

Let us assume that a model of anisotropic formation is composed of 8 sand-shale alternating layers $\left(V_{(i)}=12.5 \%\right)$ with the same thickness and resistivity: $R_{\text {sand }}=20 \mathrm{ohmm}$, and $R_{s h}=1 \mathrm{ohmm}$ (Fig. 8). Applying Eqs. 8 and 9 for a laminar model we get $R_{V}=10.5 \mathrm{ohmm}$ and $R_{H}=1.9 \mathrm{ohmm}$. These are the same values as obtained from the model (b) (Fig. 7). Hence, that represents a low-resistivity formation. In vertical and slightly inclinated wells, a traditional induction tool records the horizontal resistivity $R_{H}$ which is strongly dependent on low-resistivity shale interbeds and poorly indicates hydrocarbon saturation.

In their paper, Ferraris and co-authors (Ferraris et al. 2007) emphasize that measuring the horizontal and vertical resistivity of anisotropic rocks in vertical or slightly inclinated wells, represents a serious problem for conventional induction tools and laterologs. Faivre et al. (2002) studied the distributions of current lines from induction tools and laterologs with different electrode configurations and they are of the opinion that laterolog tools respond more to the vertical component. However, when the invaded zone is deep $(D i>30-50 \mathrm{~cm})$, then the sensitivity to the vertical component is too small to be used for the evaluation of $R_{V}$. 


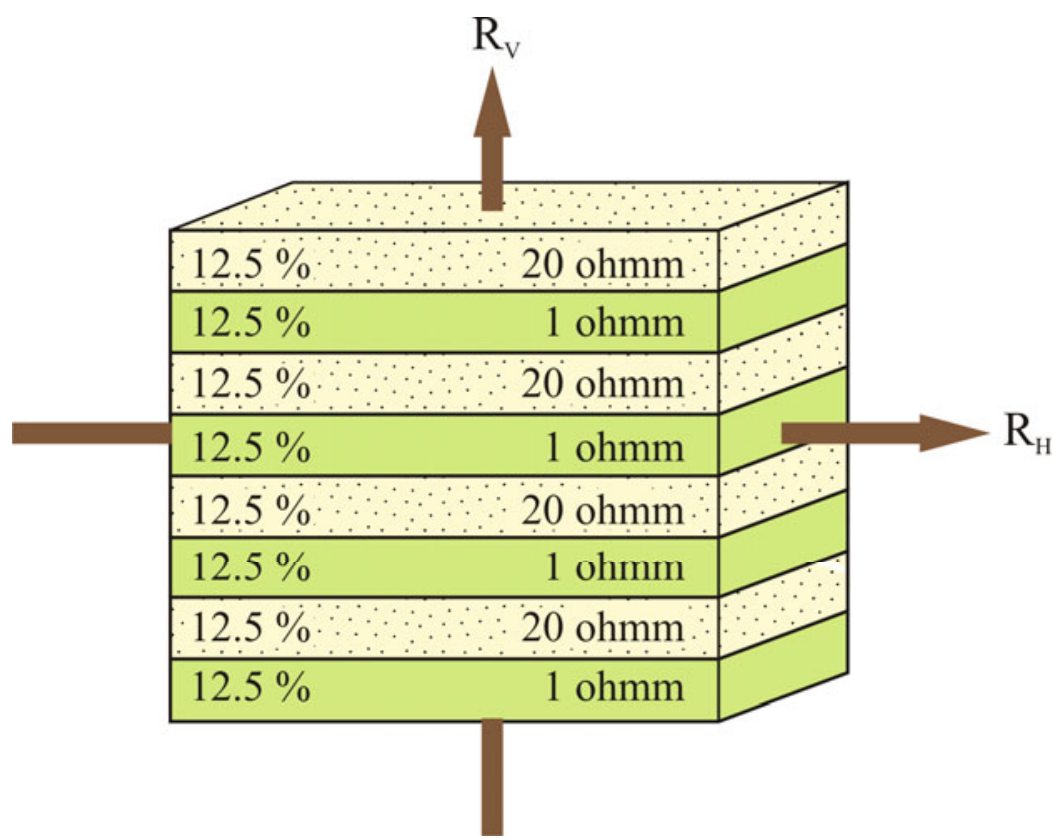

Fig. 8. Model of anisotropic rock consisting of a sequence of eight alternate layers of sand and shale with the same thickness (Bała 2011).

The current lines around deep laterolog tools (LLD) are almost horizontal, although their configuration is rather disturbed in anisotropic media. Faivre et al. (2002) concludes that shallow laterolog (LLS) and spherically focused $\log$ (SFL) devices are more sensitive to medium's anisotropy, however the mud filtration can decrease or even conceal the anisotropy (Moran and Gianzero 1979).

\subsection{Estimation of errors}

Anderson and Barber (1996) have evaluated that the accuracy of a conventional induction tool (AIT) amounts to $2 \%$ of the relative error when the tool measures resistivity of less than $25 \mathrm{ohmm}$.

In their respective papers, Yin (2000) and Yin and Kurniawan (2008) show that the accuracy of induction tool measurement is $\pm 0.02 \mathrm{ohmm}$ for a resistivity range of 1 to $10 \mathrm{ohmm}, \pm 0.54 \mathrm{ohmm}$ for resistivity of $25 \mathrm{ohmm}$, and $\pm 7.5 \mathrm{ohmm}$ for resistivity of $100 \mathrm{ohmm}$.

Starting with the simplest models of series and parallel connections of resistors and transforming Eqs. 8 and 9, one can calculate the resistivity of sand interbedding, $R_{\text {sand }}$. 
a)

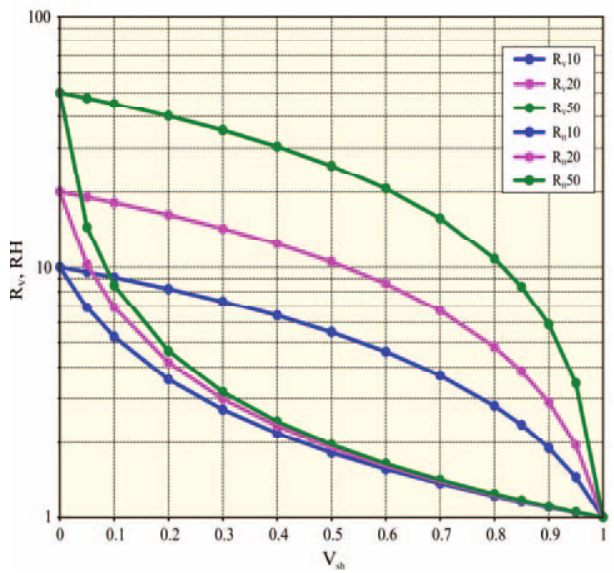

b)

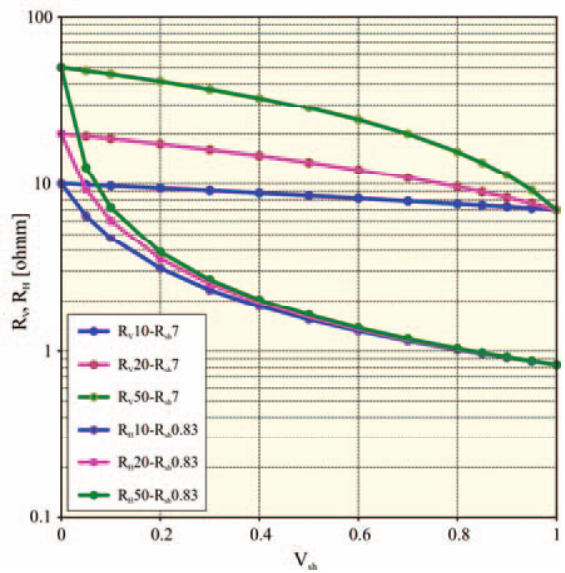

Fig. 9. Resistivity $R_{V}$ and $R_{H}$ calculations based on a model of series connection and parallel connection of resistors as a function of shale volume. It was assumed that $R_{\text {sand }}=10,20,50 \mathrm{ohmm}$, and (a) $R_{\text {sh }}=1 \mathrm{ohmm}$, isotropic shale; and (b) intrinsic anisotropy of shale: $R_{s h H}=0.83 \mathrm{ohmm}, R_{s h V}=7.0 \mathrm{ohmm}$.

For series connection:

$$
R_{\text {sand }}=\frac{R_{V}-R_{s h} \cdot V_{s h}}{1-V_{s h}}
$$

and for parallel connection:

$$
R_{\text {sand }}=\frac{R_{H} \cdot R_{s h} \cdot\left(1-V_{s h}\right)}{R_{s h}-R_{H} \cdot V_{s h}}
$$

Figure 9 presents resistivities $R_{V}$ and $R_{H}$ versus shale volume calculated for both models (series connection and parallel connection), for $R_{\text {sand }}=10$, 20 and $50 \mathrm{ohmm}$; and (a) isotropic shales with $R_{s h}=1 \mathrm{ohmm}$ (Fig. 9a); and (b) shales with intrinsic anisotropy with resistivity based on logs from well C-3: $R_{s h H}=0.83 \mathrm{ohmm}$ and $R_{s h V}=7.0 \mathrm{ohmm}$ (Fig. 9b).

Similar calculations as for the model (a) but for the other parameters were presented byYin and Kurniawan (2008).

It can be observed in the curves that:

- All three values of $R_{H}$ overlap for shale volume $V_{s h}>50 \%$ and this may result in considerable ambiguity in the $R_{\text {sand }}$ calculation if the parallel connection model is solely applied.

- $R_{V}$ values have good resolution for different $R_{\text {sand }}$ when $V_{s h}$ ranges from 0 to $95 \%$. Using a series connection model gives a proper evaluation of $R_{\text {sand }}$ which is of considerable importance for further quantitative interpre- 
tation of anisotropic formations. This is valid both for isotropic shales and shales with intrinsic anisotropy.

\section{AN ATTEMPT TO ASSESS WATER SATURATION $\boldsymbol{S}_{W}$}

An attempt to assess water and gas saturation was made using the approach described in the literature (Klein 1993, Minh et al. 2007, Bała 2011). The method consists in generating cross-plots based on the calculated resistivities, $R_{H}$ and $R_{V}$ (Fig. 10). In the cross-plots there are templates characterizing two families of curves: $R_{\text {sand }}$ and $V_{s h}$. When the coordinates of the "shale" point were $R_{s h V}=R_{s h H}=1 \mathrm{ohmm}$ (isotropic shales), a number of points interpreted for a depth interval of 1065 to $1100 \mathrm{~m}$ in well C-3 did not fall within the range of these $R_{\text {sand }}$ and $V_{s h}$ values (Fig. 10a). This may indicate the intrinsic anisotropy of shales. After the shale point had been shifted to $R_{s h V}=7.0 \mathrm{ohmm}$ and $R_{s h H}=0.83 \mathrm{ohmm}$, all points were within the "grid template" for $R_{\text {sand }}$ and $V_{\text {sh }}$ (Fig. $10 \mathrm{~b}$ ).

The resistivity of sandstone layers $\left(R_{\text {sand }}\right)$ and shale volume $\left(V_{s h}\right)$ were calculated. The resistivity of water-bearing zone $\left(R_{\mathrm{o}}\right)$ can be also read from the cross-plot (Fig. 10b) at line $R_{V}=R_{H}$ (which runs at an angle of $45^{\circ}$ ). The line linking $R_{\mathrm{o}}$ with the shale point delimits the area $S w=1$ from the area $S w<1$, which is on the right of the $R_{\mathrm{o}}$ line. This mirrors the assumption that all sandstone beds have a similar porosity.

Water saturation and hydrocarbon saturation for selected levels with electric anisotropy were calculated with the use of commonly known
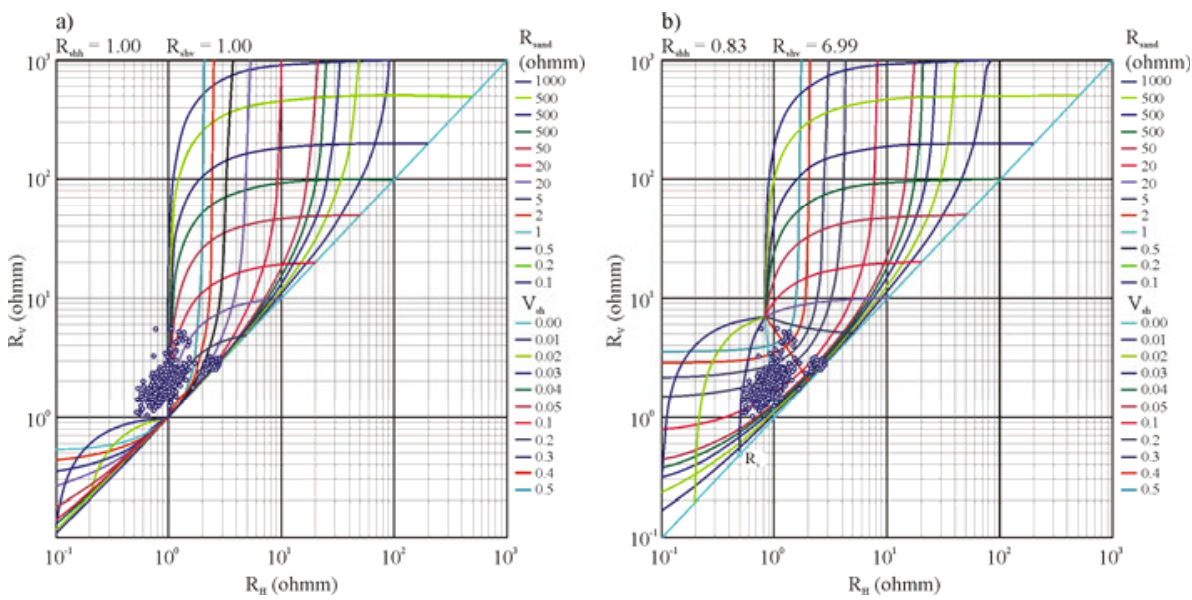

Fig. 10. Cross-plots $R_{H}=f\left(R_{V}\right)$ for Miocene formations in the Cierpisz-3 well at a depth interval of $1065-1100 \mathrm{~m}$ with templates showing values for $R_{\text {sand }}$ and $V_{s h}$ : (a) isotropic shales, and (b) intrinsic anisotropy of shales. 

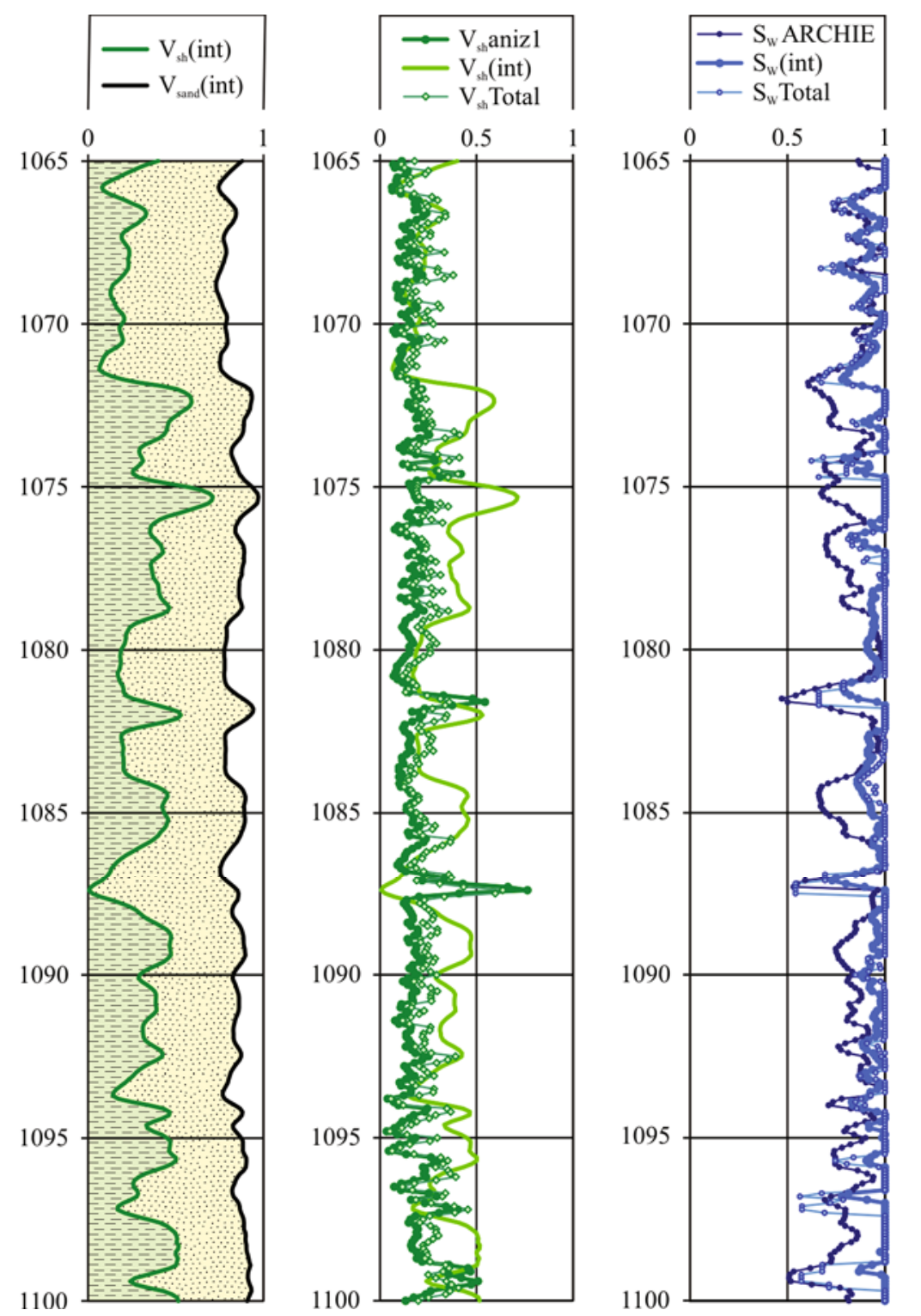

Fig. 11. $V_{s h}$ and $S_{W}$ calculated by applying the anisotropic procedure and routine quantitative interpretation made by Geofizyka Kraków: $V_{s h}($ int $), S_{w}($ int).

Archie's, Simandoux's, Total, Indonesian, and Waxman-Smits' equations. They are included in the procedure that was based on the above-described cross-plots (Fig. 10). From the $R_{\text {sand }}$ and $V_{s h}$ values determined from the cross-plots and the suitably shifted shale point and known (or assumed) po- 
rosity value, data sets containing calculated water saturation, $S_{W}$, were generated.

In this way, the saturation level $\left(S_{W} \mathrm{ARCH} 1\right)$ and $\left(S_{W} \mathrm{TOT}\right)$ was calculated for the whole depth interval of 1065-1100 $\mathrm{m}$ and was then compared with routine interpretations $\left(S_{W}(\right.$ int $\left.)\right)$ made by Geofizyka Kraków (C-3 Well 2004). The results are shown in Fig. 11. The results are generally compatible although discrepancies can be observed over some intervals.

Though it slightly deforms the "grid template", shifting the shale point towards lower values of $R_{s h H}$ has a minimal impact on the calculated values of $R_{\text {sand }}$ and $V_{s h}$, while decreasing $R_{s h V}$ causes a significant decrease in $S_{W}$ and increase in $V_{s h}$. Thus, as a result of an improper choice of the shale point one can get a reading that is either too high or too low $S_{W}\left(S_{G}\right)$.

Therefore, points in the "grid template" should be carefully studied before choosing the point of intrinsic anisotropy of shales.

The presented method is based on cross-plots and gives an initial evaluation of water and gas saturation based on calculated values of $R_{H}$ and $R_{V}$ and estimated $R_{\text {sand }}$ and $V_{s h}$.

The method is independent of results of an integrated interpretation of well logging data and allows saturation in anisotropic levels to be roughly evaluated.

\section{CONCLUSIONS AND DISCUSSION}

Anisotropy parameters were calculated based on resistivity logs recorded with a laterolog tool (DLL) and induction tool HRAI, in Miocene formations in well C-3.

It can be observed that the calculated electric anisotropy coefficient is highly variable and ranges from 1 to 2.2 , while only locally does it exceed 2.3. The increase in the anisotropy coefficient value usually corresponds to zones with a higher shale volume that are interbedded with sandstones and mudstones.

The examination of calculated electric anisotropy coefficients should include the following elements:

a Elimination of intervals with resistivity changes near the well due to infiltration of the mud filtrate that can result in possible equivalence.

- A detailed study of high-resolution logs recorded with a dipmeter SED that can prove the possible presence of anisotropic levels.

a Higher gas saturation and higher porosity cause an increase in $R_{V}$ which results in greater values of $\lambda$ but does not correspond to the anisotropic zones.

- It is very important to correctly evaluate the resistivity of sandstone interbeds when calculating water saturation $\left(S_{W}\right)$ and hydrocarbon saturation 
$\left(S_{G}\right)$, in the course of an integrated quantitative interpretation of anisotropic formations.

- Calculation of resistivities $R_{H}$ and $R_{V}$, as a function of depth for the assumed models, gives a better understanding of the effects of anisotropy on the resistivity measured.

- Evaluation of water and hydrocarbon saturation based on cross-plots created on the basis of calculated horizontal resistivity $R_{H}$ and vertical resistivity $R_{V}$, can provide early information on saturation in anisotropic parts of a deposit.

This method is independent of the results of a comprehensive interpretation of well logging data and allows one to estimate the hydrocarbons and water saturation level of the anisotropic zones.

Acknowledgements. The paper is part of research project NN525 363537 led by Prof. M. Bała (in 2009-2012) and research project NN307 294439 (2010-2013) financed by The National Science Center, Poland led by Prof. J. Jarzyna (2010-2013).

\section{References}

Anderson, B., and T. Barber (1996), Induction logging, Schlumberger, http://www. hub.slb.com/index.cfm?id=id8880.

Anderson, B.I., T.D. Barber, and T.M. Habashy (2002), Interpretation and inversion of fully triaxial induction data, A sensitivity study. In: Proc SPWLA 43th Ann. Logg. Symp., 2-5 June 2002, Oiso, Japan, SPWLA-2002-O.

Anderson, B., T. Barber, R. Bastia, K.R. Saxena, A.K. Tyagi, J.-B. Clavaud, B. Coffin, M. Das, R. Hayden, T. Klimentos, C.C. Minh, and S. Williams (2008), Triaxial induction - A new angle for an old measurement, Oilfield Rev.: Summer 20, 2, 64-84.

Bała, M. (2009), Study of the effects of anisotropy and shaliness on velocities of longitudinal and shear waves and other elastic parameters of clastic rocks, Geologia 35, 2/1, 559-566 (in Polish, abstract in English).

Bała, M. (2011), Evaluation of electric parameters of anisotropic sandy-shaly miocene formations on the basis of resistivity logs, Acta Geophys. 59, 5, 954966, DOI: 10.2478/s11600-011-0033-1.

Bittar, M.S., and P.F. Rodney (1994), The effects of rock anisotropy on MWD electromagnetic wave resistivity sensors. In: Proc. SPWLA 35th Ann. Logg. Symp., 19-22 June 1994, Tulsa, USA, SPWLA-1994-PP.

C-3 Well (2004), Final documentation of C-3 well, Geofizyka, Kraków. 
Chemali, R., S.C. Gianzero, and S.M. Su (1987), The effect of shale anisotropy on focused resistivity devices. In: Proc. SPWLA 28th Ann. Logg. Symp., 29 June - 2 July 1987, London, England, SPWLA-1987-H.

Dachnov, W.N. (1967), Electric and Magnetic Methods of Logging. Fundament of Theory, Nedra, Moskwa (in Russian).

Faivre, O., T. Barber, L. Jammes, and D. Vuhoang (2002), Using array induction and array laterolog data to characterize resistivity anisotropy in vertical wells. In: Proc. SPWLA 43th Ann. Logg. Symp., 2-5 June 2002, Oiso, Japan, SPWLA-2002-M.

Ferraris, P., M.R. Coutinho, A.A.G. Meira, and T. Adams (2007), Campos basin anisotropic turbidities formation evaluation: challenges and proposed solutions. In: Proc. SPWLA 48th Ann. Logg. Symp., 3-6 June 2007, Austin, USA, SPWLA-2007-QQ.

Hagiwara, T. (1996), A new method to determine horizontal-resistivity in anisotropic formations without prior knowledge of relative dip. In: Proc. SPWLA 37th Ann. Logg. Symp., 16-19 June 1996, New Orleans, USA, SPWLA1996-Q.

Karnkowski, P. (1999), Oil and Gas Deposits in Poland, Geosynoptics Society „GEOS”, Kraków, 380 pp.

Klein, J.D. (1993), Induction $\log$ anisotropy corrections, The Log Analyst 34, 2, 18-27.

Klein, J.D., P.R. Martin, and D.F. Allen (1995), The petrophysics of electrically anisotropic reservoirs. In: Proc SPWLA 36th Ann. Logg. Symp., 26-29 June 1995, Paris, France, SPWLA-1995-HH.

Kunz, K.S., and J.H. Moran (1958), Some effects of formation anisotropy on resistivity measurements in boreholes, Geophysics 23, 4, 770-794, DOI: 10.1190/1.1438527.

Minh, C.C., J.B. Clavaud, P. Sundararaman, S. Froment, E. Caroli, O. Billon, G. Davis, and R. Fairbairn (2007), Graphical analysis of laminated sandshale formations in the presence of anisotropic shales. In: Proc. SPWLA 48th Ann. Logg. Symp., 3-6 June 2007, Austin, USA, SPWLA-2007-MM.

Mollison, R.A., O.N. Fannini, B.F. Kriegshauser, L. Yu, G. Ugueto, and J. van Popta (2001), Impact of multicomponent induction technology on a deepwater turbidite sand hydrocarbon saturation evaluation. In: Proc. SPWLA 42th Ann. Logg. Symp., 17-20 June 2001, Houston, USA, SPWLA-2001-T.

Moran, J.H., and S. Gianzero (1979), Effects of formation anisotropy on resistivitylogging measurements, Geophysics 44, 7, 1266-1286, DOI: 10.1190/ 1.1441006 .

Myśliwiec, M. (2004), The Miocene reservoir rocks of the Carpathian Foredeep, Geol. Rev. 52, 7, 581-592 (in Polish, abstract in English).

Quirein, J., B. Donderici, D. Torres, E. Murphy, and J. Witkowsky (2012), Evaluation of general resistivity density-based saturation in thin, laminated sand- 
shale sequences. In: AAPG Int. Conf. Exhib. "Asia Pacific Resources: Fueling the Future”, 16-19 September 2012, Singapore.

Rosthal, R., T. Barber, S. Bonner, K.-Ch. Chen, S. Davydycheva, G. Hazen, D. Homan, C. Kibbe, R. Schlein, L. Villegas, H. Wang, and F. Zhou (2003), Field test results of an experimental fully-triaxial induction tool. In: Proc. SPWLA 44th Ann. Logg. Symp., 22-25 June 2003, Galveston, USA, SPWLA-2003-QQ.

Syrek-Moryc, C. (2006), The deposit of natural gas Cierpisz as an important point in the issues concerning the future search in the thin strata of Miocene deposits of the Carpathian Foredeep and potential natural gas resources connected with the deposits, Prace Inst. Nafty $i$ Gazu 137, 223-230 (in Polish, abstract in English).

Tabanou, J.R., P. Cheung, Ch.B. Liu, S. Hansen, J. Lavigne, T. Pickens, T. Borbas, and B. Wendt (2002), Thinly laminated reservoir evaluation in oil-base mud: High resolution versus bulk anisotropy measurement - A comprehensive evaluation. In: Proc. SPWLA 43rd Ann. Logg. Symp., 2-5 June 2002, Oiso, Japan, SPWLA-2002-P.

Yang, W. (2001), Determining resistivity anisotropy by joint lateral and induction logs. In: Proc. SPWLA 42nd Ann. Logg. Symp., 17-20 June 2001, Houston, USA, SPWLA-2001-CC.

Yin, H. (2000), Limitations and error inherent in resistivity log inverse modeling for formation evaluation. In: SEG 70th Ann. Int. Meeting Exp. Abstr., 6-11 August 2000, Calgary, Canada, SEG-2000-1798, 1798-1801.

Yin, H., and B. Kurniawan (2008), Resistivity anisotropy models and multicomponent induction measurements: Impact on Sw and uncertainty on $\mathrm{Hpv}$ estimation. In: Proc. SPWLA 48th Ann. Logg. Symp., 25-28 May 2008, Austin, USA, SPWLA-2008-LLLL.

Zajkowskij, I.J., D.E. Kowalenko, and A.E. Kulinkowich (1965), Opriedelenie parametrow anizotropowego plasta po kriwym Bokowogo Karotażnogo Zondirowania (BKZ), Prikl. Geofiz. 46, 213-216 (in Russian).

Received 13 February 2014

Received in revised form 12 May 2014

Accepted 4 July 2014 